\title{
12. PALEOMAGNETIC STUDY OF SEDIMENTS FROM DEEP SEA DRILLING PROJECT LEG 59
}

\author{
B. Keating, Hawaii Institute of Geophysics, Honolulu, Hawaii
}

\section{INTRODUCTION}

Paleomagnetic studies were conducted on the sediments from Sites 447, 448, and 450. At Sites 449 and 451 two additional holes were drilled but were not sampled for paleomagnetic study. The sediments from Hole 449 showed considerable drilling disturbance. Furthermore, much of the sedimentary sequence acquired at Site 449 consisted of dark brown pelagic clays. Extensive paleomagnetic studies on this particular lithology have been reported by Opdyke and Foster (1970) and Johnson et al. (1975). This sediment type has been shown to display unstable magnetism, related to chemical alteration. Within Hole 451, abundant faults, folds, slumps, and tectonic tilting of units was obvious; therefore, like 449 , it appeared to be an unlikely candidate for successful paleomagnetic study.

\section{SAMPLING AND MEASUREMENT PROCEDURE}

Oriented sediment samples were collected in two ways. In the most consolidated or massive portions of the cores, $2.5-\mathrm{cm}$-diameter cylindrical samples were drilled from the core with a diamond drill bit and then cut to $2.5-\mathrm{cm}$ lengths. Later, during shore lab studies, $1-\mathrm{cm}$ cubes were cut from the core and measured in cubic plastic sample boxes. The procedure was to restrict sampling to core segments longer than the core diameter in order to eliminate segment inversions that may have taken place in drilling. This convention could not be followed, however, in sampling the basalt sediments of certain cores because of their fragmentary nature. An arrow marking the up direction was scribed along the center of the split core face. Each segment was then lifted from the core tray, and a sample was drilled at right angles to, and centered on, the orientation scribe. A similar procedure was used to cut the $1-\mathrm{cm}$ cubic samples.

The sediment samples collected on board ship were originally measured on the ship's Digico spinner magnetometer. Subsequently, the samples were again measured on a 3 -inch vertical-axis SCT cryogenic magnetometer and on a Schonstedt spinner magnetometer at the Hawaii Institute of Geophysics. In general, directions derived from the various magnetometers differed by no more than 2 to 3 degrees. Many of the samples were demagnetized on the ship using the three-axis Schonstedt alternating field demagnetizing equipment. Those samples demagnetized in the Honolulu laboratory were demagnetized within a three-axis tumbler. Demagnetization studies and measurements at Hawaii Institute of Geophysics were conducted within a doubly shielded mu-metal room (ambient field $=100$ gammas).

Sample identification numbers used in this chapter consist of hole, core, and section number, followed by depth (in $\mathrm{cm}$ ) within the section at which the sample was collected.

\section{HOLE 447A}

In Hole $447 \mathrm{~A}$ the sedimentary sequence consisted of a brief section of red brown pelagic clay underlain by sedimentary breccias. For the most part the pelagic clays were unconsolidated and displayed considerable drilling disturbance. Thus most of this sequence was not suitable for paleomagnetic study, and only seven samples were collected. Five of these samples came from rock types that would be expected to give unreliable paleomagnetic directions. These were Samples 447A-5-2, 76 and 447A-10-1, 105, from the red brown pelagic clays; Sample 447A-6-7, 39, from a conglomerate unit; and Samples 447A-12-7, 1 and 447A-12-7, 10, from a breccia unit. The remaining samples were $447 \mathrm{~A}-10-2$, 49, an intensely mottled gray green clay that overlies a sedimentary breccia, and 447A-10-2, 121, a green black volcanic tuff that separates two basalt-derived sedimentary breccias. The latter two samples are middle Oligocene.

Paleomagnetic directions for alternating field demagnetization between 0 and 999 Oe are given in Table 1 . Stereonet projections of the changes in sample directions on demagnetization are shown in Figure 1. Since DSDP core samples are oriented relative to inclination only, the samples cannot be compared to one another. The stereonet projections, however, show us that the samples, with the exception of 447A-10-1, 105 and 447A-10-2, 49, have very shallow inclinations consistent with magnetization within equatorial latitudes. Sample $447 \mathrm{~A}-10-2,121$ is conspicuous because its inclination is high but shallows upon demagnetization. Samples 447A-5-2, 76, 447A-6-7, 39, 447A-10-1, 105, and 447A10-2, 49 display little change in inclination on demagnetization $\left(4.6^{\circ}-17.6^{\circ}\right)$, but their declinations continue to change on demagnetization $\left(14.9^{\circ}-57.6^{\circ}\right)$. Samples 447A-10-2, 121, 447A-12-7, 1, and 447A-12-7, 10 show larger changes in both the inclination $\left(27.9^{\circ}-81.1^{\circ}\right)$ and declination $\left(17.0^{\circ}-57.6^{\circ}\right)$. Samples $447 \mathrm{~A}-10-1,105$ and 447A-10-2, 49 display significantly steeper inclinations than the remainder of the sediments from the site. On demagnetization these samples consistently remain steeper than should be expected for this site. Plots of normalized intensity with demagnetization are shown in Figure 2. Samples 447A-5-2, 76, 447A-10-2, 49, 447A$10-2,121$ and 447A-12-7, 10 display increases in intensity at low demagnetization fields. This behavior is interpreted as the removal of a secondary component of magnetization directed in opposition to the primary component of reversed polarity. Samples 447A-6-7, 39 and 447A-12-7-1 show gradual losses in intensity on demagnetization. Sample 447A-10-1, 105, on the contrary, shows a large initial drop in intensity at low fields, indicating that a low coercivity (presumably secondary) component of magnetization that makes a significant contribution to the natural remanent magnetization (NRM) has been removed. Sample directions after demagnetization to $150 \mathrm{Oe}$ are plotted stratigraphically in Figure 3 and summarized in Table 2.

The mean paleoinclination for these samples after demagnetization was $19.8^{\circ}(\mathrm{SD}=19.8)$. This translates into a paleolatitude of $10.2^{\circ}$. Many of the rock types, 
Table 1. Summary of NRM and demagnetized sample directions, Hole 447A.

\begin{tabular}{|c|c|c|c|c|c|c|}
\hline $\begin{array}{l}\text { Core/Section/Depth } \\
(\mathrm{cm})\end{array}$ & $\begin{array}{l}\text { Cleaning Level } \\
\text { (AF) }\end{array}$ & Stability Index ${ }^{a}$ & $\begin{array}{l}\text { Declination } \\
\left({ }^{\circ}\right)\end{array}$ & $\begin{array}{l}\text { Inclination } \\
\left({ }^{\circ}\right)\end{array}$ & $\begin{array}{l}\text { Normalized Intensity } \\
{[\mathrm{J}(\mathrm{H}) / \mathrm{J}(\mathrm{O})]}\end{array}$ & $\begin{array}{l}\text { Intensity } \\
\left(\mathrm{emu} / \mathrm{cm}^{3}\right)\end{array}$ \\
\hline $5-2,76$ & 0.0 & 64.070 & 210.78 & -13.88 & 1.0000 & $0.1041 \times 10^{-3}$ \\
\hline $5-2,76$ & 50.0 & 70.960 & 212.75 & -16.45 & 1.0355 & $0.1078 \times 10^{-3}$ \\
\hline $5-2,76$ & 100.0 & 133.759 & 215.86 & -13.97 & 0.9885 & $0.1029 \times 10^{-3}$ \\
\hline $5-2,76$ & 150.0 & 126.952 & 225.24 & -11.67 & 0.7866 & $0.8188 \times 10^{-4}$ \\
\hline $5-2,76$ & 300.0 & 64.511 & 228.67 & -20.80 & 0.5174 & $0.5386 \times 10^{-4}$ \\
\hline $6-7,39$ & 0.0 & 741.134 & 296.87 & -0.83 & 1.0000 & $0.1337 \times 10^{-3}$ \\
\hline $6-7,39$ & 50.0 & 361.637 & 264.24 & -18.40 & 1.1593 & $0.1550 \times 10^{-3}$ \\
\hline $6-7,39$ & 100.0 & 38.640 & 263.65 & -18.47 & 1.1122 & $0.1487 \times 10^{-3}$ \\
\hline $6-7,39$ & 150.0 & 126.823 & 264.11 & -15.20 & 0.9372 & $0.1253 \times 10^{-3}$ \\
\hline $6-7,39$ & 200.0 & 167.501 & 273.66 & -17.44 & 0.8197 & $0.1096 \times 10^{-3}$ \\
\hline $6-7,39$ & 300.0 & 147.355 & 258.96 & -13.79 & 0.5878 & $0.7859 \times 10^{-4}$ \\
\hline $10-1,105$ & 0.0 & 127.992 & 38.33 & 40.77 & 1.0000 & $0.1210 \times 10^{-3}$ \\
\hline $10-2,105$ & 25.0 & 360.956 & 34.12 & 40.50 & 0.8950 & $0.1083 \times 10^{-3}$ \\
\hline $10-1,105$ & 50.0 & 403.709 & 23.45 & 53.94 & 0.9091 & $0.1100 \times 10^{-3}$ \\
\hline $10-1,105$ & 100.0 & 193.537 & 38.36 & 49.42 & 0.7293 & $0.8824 \times 10^{-4}$ \\
\hline $10-1,105$ & 150.0 & 114.261 & 45.29 & 42.44 & 0.5494 & $0.6648 \times 10^{-4}$ \\
\hline $10-1,105$ & 200.0 & 50.206 & 43.38 & 44.86 & 0.4164 & $0.5038 \times 10^{-4}$ \\
\hline $10-1,105$ & 300.0 & 44.952 & 41.97 & 49.26 & 0.2310 & $0.2795 \times 10^{-4}$ \\
\hline $10-2,49$ & 0.0 & 28.392 & 229.92 & 53.92 & 1.0000 & $0.1648 \times 10^{-3}$ \\
\hline $10-2,49$ & 100.0 & 107.401 & 230.48 & 51.10 & 0.9448 & $0.1557 \times 10^{-3}$ \\
\hline $10-2,49$ & 150.0 & 186.384 & 244.81 & 55.78 & 0.6402 & $0.1055 \times 10^{-3}$ \\
\hline $10-2,121$ & 0.0 & 577.046 & 323.48 & -72.65 & 1.0000 & $0.3341 \times 10^{-4}$ \\
\hline $10-2,121$ & 25.0 & 1083.496 & 295.18 & -60.95 & 0.7836 & $0.2618 \times 10^{-4}$ \\
\hline $10-2,121$ & 50.0 & 885.835 & 282.11 & -26.76 & 0.8007 & $0.2675 \times 10^{-4}$ \\
\hline $10-2,121$ & 100.0 & 176.283 & 274.13 & -12.41 & 0.9156 & $0.3059 \times 10^{-4}$ \\
\hline $10-2,121$ & 150.0 & 230.676 & 274.80 & -11.29 & 0.7695 & $0.2571 \times 10^{-4}$ \\
\hline $10-2,121$ & 200.0 & 440.445 & 265.63 & 8.50 & q0.6181 & $0.2065 \times 10^{-4}$ \\
\hline $10-2,121$ & 300.0 & 445.506 & 270.84 & -35.85 & 0.4056 & $0.1355 \times 10^{-4}$ \\
\hline $12-7,1$ & 0.0 & 155.459 & 184.08 & 18.67 & 1.0000 & $0.2250 \times 10^{-5}$ \\
\hline $12-7,1$ & 25.0 & 235.815 & 182.73 & 22.34 & 1.1867 & $0.2670 \times 10^{-5}$ \\
\hline $12-7,1$ & 100.0 & 176.153 & 186.92 & -1.03 & 1.1867 & $0.2670 \times 10^{-5}$ \\
\hline $12-7,1$ & 250.0 & 26.714 & 182.06 & -3.31 & 0.8489 & $0.1910 \times 10^{-5}$ \\
\hline $12-7,1$ & 400.0 & 35.858 & 180.19 & -5.20 & 0.7022 & $0.1580 \times 10^{-5}$ \\
\hline $12-7,1$ & 600.0 & 47.546 & 169.35 & -4.88 & 0.5156 & $0.1160 \times 10^{-5}$ \\
\hline $12-7,1$ & 800.0 & 46.113 & 177.55 & -4.13 & 0.4178 & $0.9400 \times 10^{-6}$ \\
\hline $12-7,10$ & 0.0 & 199.253 & 177.91 & 16.57 & 1.0000 & $0.2400 \times 10^{-5}$ \\
\hline $12-7,10$ & 25.0 & 189.688 & 176.28 & 11.84 & 1.0000 & $0.2400 \times 10^{-5}$ \\
\hline $12-7,10$ & 100.0 & 95.323 & 180.05 & -1.10 & 1.1125 & $0.2670 \times 10^{-5}$ \\
\hline $12-7,10$ & 250.0 & 29.090 & 178.56 & -1.79 & 0.9208 & $0.2210 \times 10^{-5}$ \\
\hline $12-7,10$ & 400.0 & 51.536 & 176.06 & -8.43 & 0.7333 & $0.1760 \times 10^{-5}$ \\
\hline $12-7,10$ & 800.0 & 48.238 & 171.22 & -30.37 & 0.6833 & $0.1640 \times 10^{-5}$ \\
\hline $12-7,10$ & 999.0 & 40.642 & 163.01 & -26.93 & 0.3271 & $0.7850 \times 10^{-6}$ \\
\hline
\end{tabular}

${ }^{\text {a }}$ Millidegrees per Oe.

however, cannot be expected to produce reliable paleoinclinations. The conglomerate and breccia units, however, display the expected low paleolatitudes. The uppermost red pelagic clay sample displayed a shallow inclination, $-11.6^{\circ}$. The lower one, however, showed a steep $\left(42.4^{\circ}\right)$ inclination. (Drilling disturbance precluded further sampling of this lithology.) The sample of green clay overlying a breccia unit also displayed a very steep $\left(55.7^{\circ}\right)$ inclination, perhaps suggesting tectonic rotation. In contrast, the tuff below it (same section), which was situated between two breccias, showed the expected low inclination $\left(-1.7^{\circ}\right)$. (The demagnetization studies suggest that this sample is not stably magnetized.)

On the basis of the study of available sediment samples from Hole 447A, there seem to be too few reliable samples to deduce polarity or paleolatitude from this stratigraphic sequence.

\section{HOLE 448}

Paleomagnetic studies were made on 15 sedimentary samples from Hole 448. With the exception of three samples, these rocks were gray to green tuffs. The three exceptional Samples 448-4-6, 132, 448-25-3, 91, and
448-31-1, 16 were a nannofossil ooze, claystone (turbidite), and nannofossil chalk, respectively.

The results of these paleomagnetic studies are summarized in Table 3 (unstable samples were removed from the table). Stereonet projections of the changes in magnetic direction with demagnetization are shown in Figure 4. In general, the tuffs were stably magnetized. Samples 448-20-2, 143, 448-25-1, 55, 448-25-3, 91, $448-27-1,102$, and $448-29-1,60$ are very stably magnetized. They show a strong resistance to directional change on demagnetization, as is the case with 448-24-1, 61 , a volcanic sandstone. Samples 448-20-1, 5, 448-24-2, $79,448-26-1,112$, and $448-26-2,48$ show a moderate amount of directional change in declination (14-42 ${ }^{\circ}$ ) and inclination $\left(6-21^{\circ}\right)$. Sample 448-4-6, 132, a nannofossil ooze, shows large directional changes.

Numerous samples from Hole 448 were demagnetized at demagnetization steps up to $300 \mathrm{Oe}$. The mean destructive fields were found to be roughly $150 \mathrm{Oe}$; thus the remainder of the samples were demagnetized at steps of 100 and 150 Oe alternating field. Samples 448-27-1, $112,448-20-2,143$, and 448-20-1, 5 (Fig. 5) all show increases in intensity upon magnetization. This behavior suggests that a secondary component of opposite mag- 

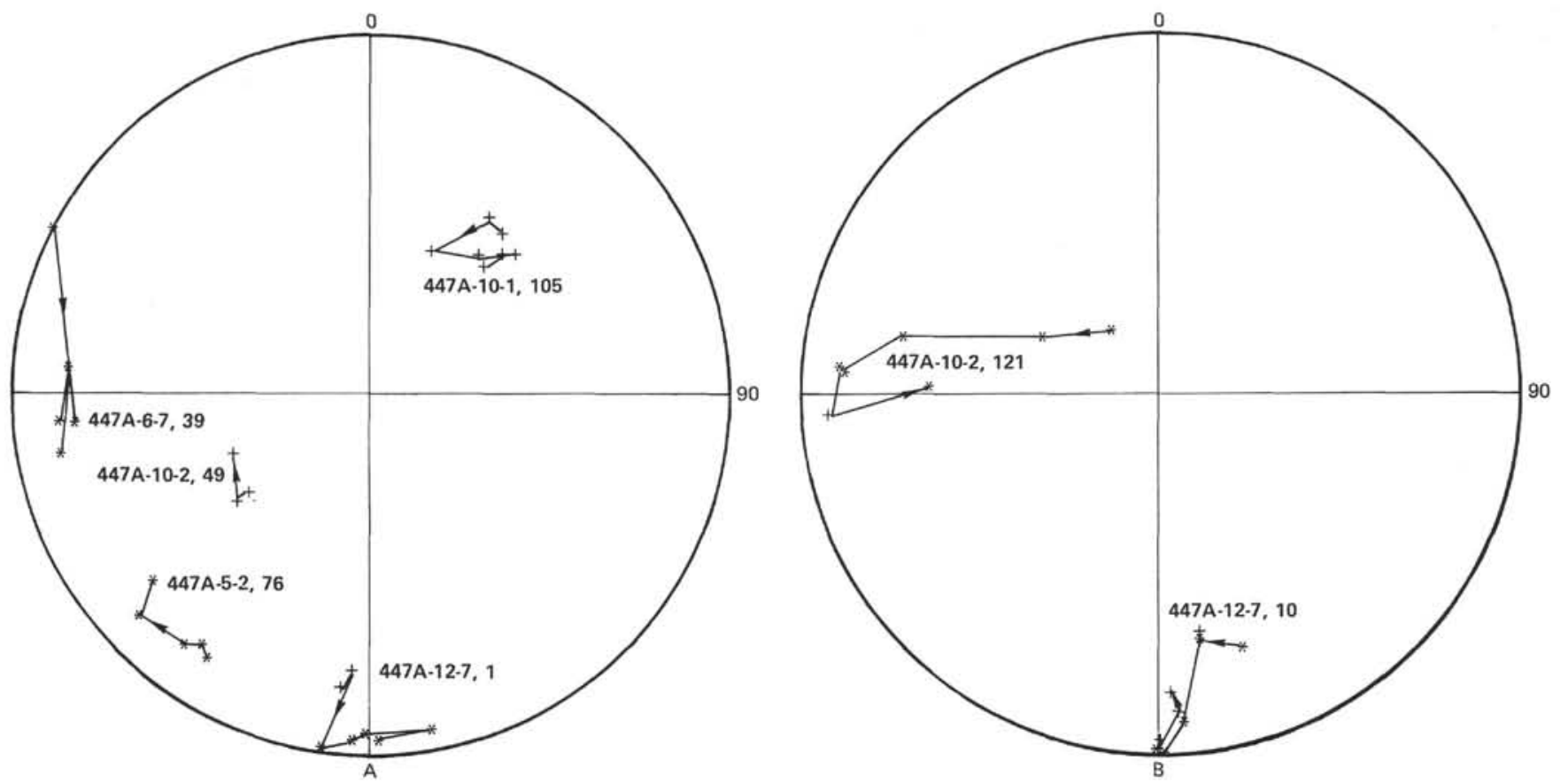

Figure 1. (A and B) Stereographic projections of the change in magnetic directions on demagnetization for samples from Hole 447A. (Arrows indicate direction of change upon progressive demagnetization, stars = negative inclination, and crosses = positive inclination.)

netization is being removed from the primary reverse magnetization. All of the remaining samples from this hole displayed gradual losses of intensity on demagnetization characteristic of deep sea sediments (Keating and Helsley, 1978a, 1978b).

A stratigraphic plot of sample inclinations is shown in Figure 3 (values in Table 2). With the exception of Sample 448-26-2, 48, the samples from this site display equatorial paleolatitudes varying from 0 to $\pm 9.5^{\circ}$. Demagnetization studies suggest that Samples 448-20-1, 5, 448-20-2, 143, and 448-27-1, 102 are reversely magnetized. The last four samples from this hole display consistent negative inclinations. Samples from Cores 20 through 27 have positive inclinations (with the exception of two single points of opposed polarity that may reflect unidentified sample inversions). Since we have no way of determining in which hemisphere the site was situated at the time of sediment deposition, it is impossible to assign the polarity to the sequence.

The mean paleolatitude was calculated from these sediments in two ways. In the first case both signs (polarities) were used, resulting in a mean which was equatorial (paleolatitude $=-0.75 ; \mathrm{SD}=11.1$ ). In the second case the sample paleolatitude values were all assigned a single polarity (i.e., the site was not exactly on the equator but near it, with both polarities present). In this case the mean paleolatitude was $4.7^{\circ}(\mathrm{SD}=5.3)$. If we calculate the mean using both polarities, a mean paleolatitude of $1.5^{\circ}$ results $(\mathrm{SD}=11.1$ ).

Accumulation rates discussed in the Site 448 report (this volume) indicate that these samples (with the exception of 448-4-6, 132, the first sample) were deposited at roughly $32 \mathrm{~m} / \mathrm{m}$.y. Using this rate, we estimate the individual samples collected to have been deposited within 300 to 800 years (depending on whether they were cubic or cylindrical samples and assuming continuous deposition). Because the sedimentation rate was so high, secular variation of the earth's magnetic field may not have been averaged out. If this is the case, then the variation in the paleolatitudes $(-9.49-8.7)$ may be a good measure of secular variation in the earth's magnetic field at the time of deposition of these sediments.

\section{HOLE 450}

Site 450 is situated in the western Parece Vela Basin. The sediments sampled at this site were vitric tuffs. Generally the tuffs were fine-grained, though some reached sand size. However, grain size does not seem to be reflected in the magnetic measurements. The basal sediments (Core 35, Section 3) appear to have undergone hydrothermal alterations, according to shipboard analyses. Thermomagnetic measurements (by Keating) and oxygen studies (by Natland) are underway on the basalt sediments and are the subjects of later papers.

Stereonet projections of the changes in magnetic directions on demagnetization are shown in Figure 6. The magnetic directions are summarized in Table 4 . Large changes in directions of magnetization, viewed as unstable magnetization, were seen in Samples 450-21-2, $52,450-17-3,86,450-17-1,18,450-21-5,61,450-26-1$, 65 , and $450-25-1,26$. Three additional samples, 450$26-3,101,450-35-3,92$, and 450-35-2, 133, displayed more moderate changes-i.e., changes of declination of $11^{\circ}$ to $21^{\circ}$ and/or changes in inclination of $5^{\circ}$ to $10^{\circ}$. The remaining samples seemed to be very stably magnetized and showed little change in direction after alternating field demagnetization.

Summaries of the changes in intensity on demagnetization are shown in Figure 7. Samples 450-17-1, 18, $450-17-3,86,450-25-1,26,450-26-1,65,450-26-3,101$, 

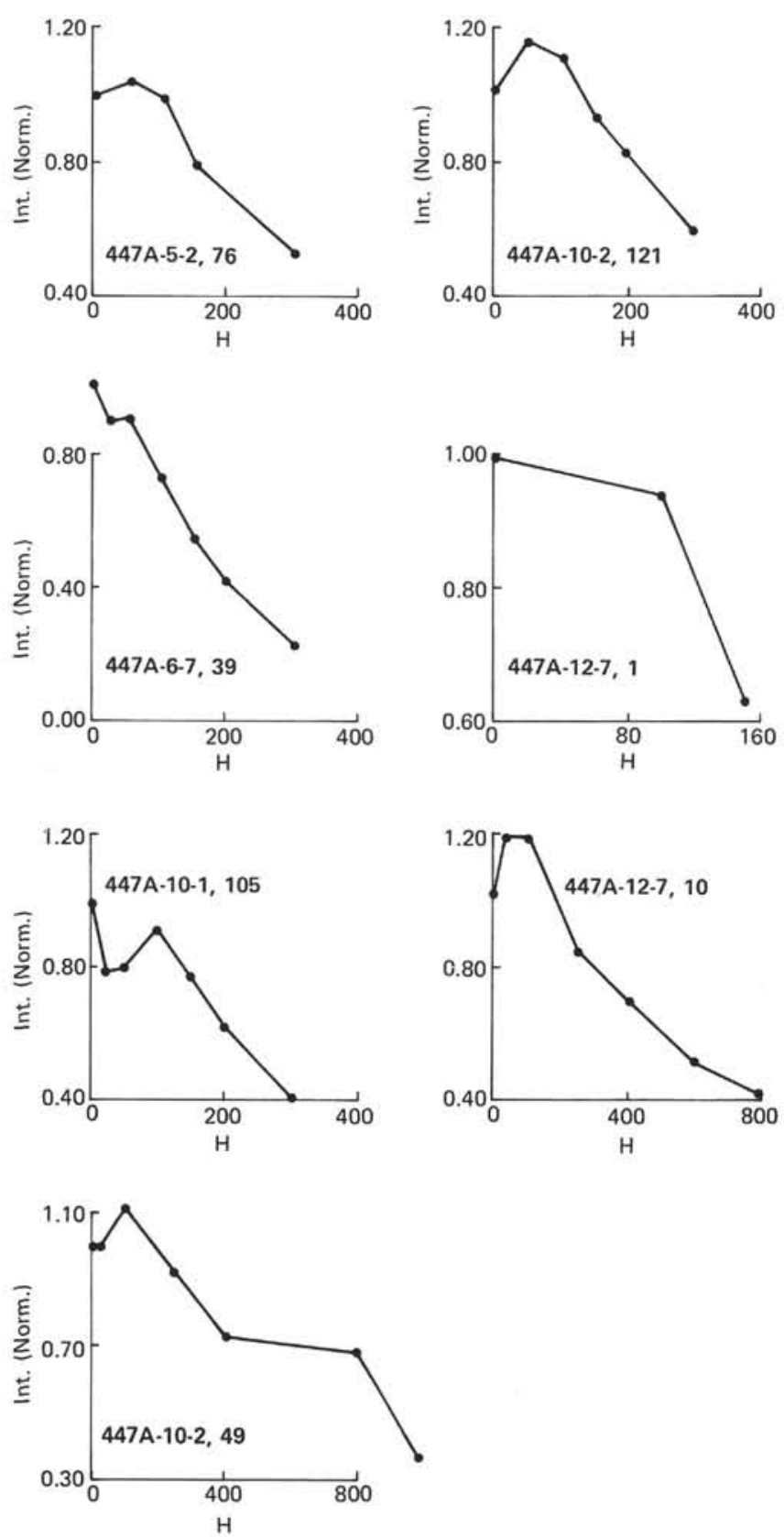

Figure 2. Plots of normalized intensity versus demagnetization field for samples from Hole 447A. (Peak alternating demagnetization fields range from 160 to $800 \mathrm{Oe}$.)

and 450-35-1, 54 all show increases in intensity on demagnetization. This increase is interpreted as the removal of a secondary component of magnetization of opposite direction from the primary component, which is reversely magnetized. The remaining samples show gradual decreases in intensity during progressive demagnetization, as is typical of marine sediments. Detailed stepwise demagnetization studies were conducted on a group of pilot samples and the mean destructive field was found to be approximately $150 \mathrm{Oe}$. The rest of the samples were demagnetized at two steps, 100 and 150 Oe.

In order to estimate the maximum paleolatitude possible for the site, the absolute values of the inclina-

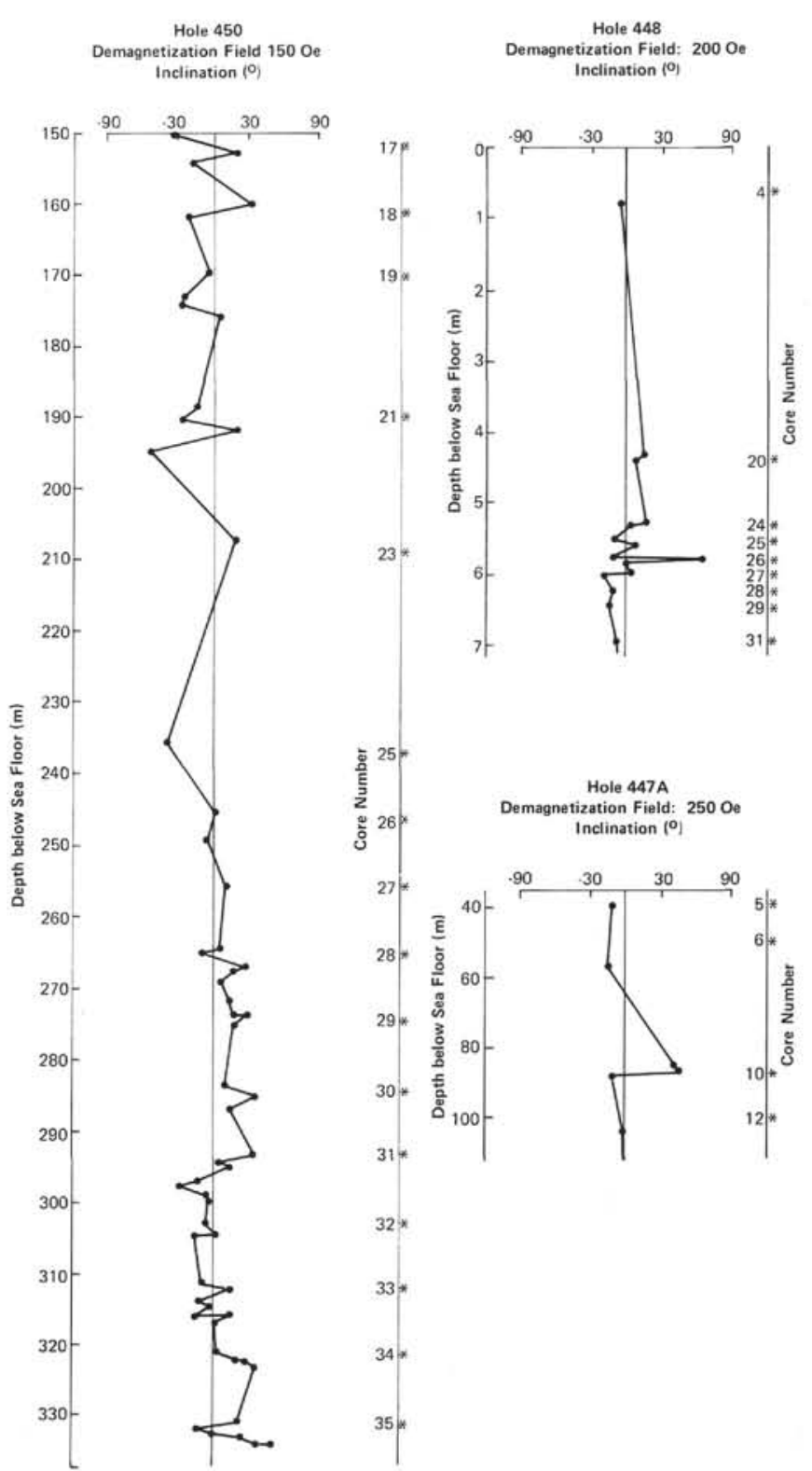

Figure 3. Stratigraphic plots of sample inclination versus depth for samples from Holes 447A, 448, and 450.

tions were used and a mean latitude of $4.7^{\circ}$ found (paleoinclination $=9.4 ; \mathrm{SD}=5.3$ ). After the six samples with unstable magnetization were removed, the mean paleolatitudes (based on sample directions after demagnetization at $150 \mathrm{Oe})$ were $7.8^{\circ}(\mathrm{SD}=10.8)$.

Paleoinclinations at this site are plotted stratigraphically in Figure 3. Above Core 27, the inclination oscillates between positive and negative. In Cores 27 through 35 , however, there appears to be a consistent polarity sequence (omitting 1-point reversals from consideration). The intervals between 250 and 295, 321 and 331 , and 333 and 334 meters depth are characterized by positive inclinations. The intervals between 297 and 316 and 331 and 332 meters depth are characterized by negative inclinations. Polarities have not been assigned to this sequence for two reasons: (1) Because the hemi- 
Table 2. Stratigraphic summary of sample inclination and intensity, Holes 447A, 448, and 450 .

\begin{tabular}{|c|c|c|c|}
\hline $\begin{array}{l}\text { Core/Section/Depth } \\
\text { (cm) }\end{array}$ & $\begin{array}{l}\text { Depth below } \\
\text { Sea Floor } \\
\text { (m) }\end{array}$ & $\begin{array}{l}\text { Inclination } \\
\left({ }^{\circ}\right)\end{array}$ & $\begin{array}{l}\text { Intensity } \\
\left(\mathrm{emu} / \mathrm{cm}^{3}\right)\end{array}$ \\
\hline \multicolumn{4}{|l|}{ Hole 447A } \\
\hline $5-2,76$ & 39.26 & -11.67 & $0.8188 \times 10^{-4}$ \\
\hline $6-7,39$ & 56.39 & -15.20 & $0.1253 \times 10^{-3}$ \\
\hline $10-1,105$ & 86.05 & 42.44 & $0.6648 \times 10^{-4}$ \\
\hline $10-2,49$ & 86.99 & 46.60 & $0.1821 \times 10^{-4}$ \\
\hline $10-2,121$ & 87.71 & -11.29 & $0.2571 \times 10^{-4}$ \\
\hline $12-7,1$ & 107.01 & -1.03 & $0.2670 \times 10^{-5}$ \\
\hline $12-7,10$ & 107.10 & -1.79 & $0.2210 \times 10^{-5}$ \\
\hline \multicolumn{4}{|l|}{ Hole 448} \\
\hline $4-6,132$ & 32.82 & -6.07 & $0.1410 \times 10^{-4}$ \\
\hline $20-1,5$ & 176.05 & 14.70 & $0.3918 \times 10^{-4}$ \\
\hline $20-2,143$ & 178.93 & 9.00 & $0.1502 \times 10^{-4}$ \\
\hline $24-2,61$ & 214.61 & 17.10 & $0.3314 \times 10^{-4}$ \\
\hline $24-2,79$ & 216.29 & 3.58 & $0.3444 \times 10^{-3}$ \\
\hline $25-1,55$ & 224.05 & -9.50 & $0.9687 \times 10^{-5}$ \\
\hline $25-3,91$ & 227.41 & 8.95 & $0.1446 \times 10^{-3}$ \\
\hline $26-1,112$ & 234.62 & -9.49 & $0.3565 \times 10^{-4}$ \\
\hline $26-2,48$ & 235.48 & 66.10 & $0.1456 \times 10^{-4}$ \\
\hline $26-3,50$ & 237.00 & 0.10 & $0.1359 \times 10^{-3}$ \\
\hline $27-1,102$ & 243.52 & 2.60 & $0.1023 \times 10^{-3}$ \\
\hline $27-2,60$ & 244.60 & -18.50 & $0.2727 \times 10^{-3}$ \\
\hline $28-1,95$ & 252.95 & -11.20 & $0.4175 \times 10^{-3}$ \\
\hline $29-1,60$ & 262.10 & -14.00 & $0.1191 \times 10^{-4}$ \\
\hline $31-1,16$ & 280.66 & -8.37 & $0.1214 \times 10^{-4}$ \\
\hline \multicolumn{4}{|l|}{ Hole 450} \\
\hline $17-1,18$ & 150.18 & -32.13 & $0.2567 \times 10^{-3}$ \\
\hline $17-2,104$ & 152.54 & 17.02 & $0.5255 \times 10^{-3}$ \\
\hline $17-3,86$ & 153.86 & -17.50 & $0.8686 \times 10^{-4}$ \\
\hline $18-1,30$ & 159.80 & 32.50 & $0.8797 \times 10^{-4}$ \\
\hline $18-2,75$ & 161.75 & -20.10 & $0.1984 \times 10^{-4}$ \\
\hline $19-1,13$ & 169.13 & -3.00 & $0.3597 \times 10^{-4}$ \\
\hline $19-3,86$ & 172.86 & -24.30 & $0.3794 \times 10^{-4}$ \\
\hline $19-4,33$ & 173.83 & -26.80 & $0.3407 \times 10^{-4}$ \\
\hline $19-5,49$ & 175.49 & 4.80 & $0.8432 \times 10^{-5}$ \\
\hline $21-1,32$ & 188.32 & -13.16 & $0.1151 \times 10^{-2}$ \\
\hline $21-2,52$ & 190.02 & -26.07 & $0.3932 \times 10^{-4}$ \\
\hline $21-3,55$ & 191.55 & 22.28 & $0.2437 \times 10^{-3}$ \\
\hline $21-5,61$ & 194.61 & -51.46 & $0.4445 \times 10^{-4}$ \\
\hline $23-1,13$ & 207.13 & 21.00 & $0.2574 \times 10^{-3}$ \\
\hline $25-1,26$ & 235.76 & -36.90 & $0.1199 \times 10^{-3}$ \\
\hline $26-1,65$ & 245.65 & 2.63 & $0.2245 \times 10^{-3}$ \\
\hline $26-3,50$ & 248.50 & -2.80 & $0.1094 \times 10^{-3}$ \\
\hline $26-3,101$ & 249.01 & -3.47 & $0.1121 \times 10^{-3}$ \\
\hline $27-1,98$ & 255.48 & 9.70 & $0.3048 \times 10^{-3}$ \\
\hline $28-1,39$ & 264.39 & 5.30 & $0.3570 \times 10^{-3}$ \\
\hline $28-1,95$ & 264.95 & -9.20 & $0.6366 \times 10^{-3}$ \\
\hline $28-2,145$ & 266.95 & 26.90 & $0.4860 \times 10^{-4}$ \\
\hline $28-3,64$ & 267.64 & 18.70 & $0.5288 \times 10^{-4}$ \\
\hline $28-4,43$ & 268.93 & 7.80 & $0.4261 \times 10^{-4}$ \\
\hline $28-5,97$ & 270.97 & 13.30 & $0.1825 \times 10^{-3}$ \\
\hline $29-1,10$ & 273.60 & 17.20 & $0.4860 \times 10^{-4}$ \\
\hline $29-1,26$ & 273.76 & 28.60 & $0.3225 \times 10^{-4}$ \\
\hline $29-2,21$ & 275.21 & 18.40 & $0.7755 \times 10^{-5}$ \\
\hline $30-1,29$ & 283.59 & 10.80 & $0.1720 \times 10^{-4}$ \\
\hline $30-2,23$ & 285.03 & 36.70 & $0.2033 \times 10^{-4}$ \\
\hline $30-3,59$ & 286.89 & 14.50 & $0.1543 \times 10^{-4}$ \\
\hline $31-1,76$ & 293.26 & 35.20 & $0.8468 \times 10^{-5}$ \\
\hline $31-2,28$ & 294.28 & 2.90 & $0.1273 \times 10^{-4}$ \\
\hline $31-2,103$ & 295.03 & 12.50 & $0.1031 \times 10^{-4}$ \\
\hline $31-4,5$ & 297.05 & -14.80 & $0.8961 \times 10^{-5}$ \\
\hline $31-4,82$ & 297.82 & -29.72 & $0.1232 \times 10^{-3}$ \\
\hline $31-5,75$ & 299.25 & -7.10 & $0.1025 \times 10^{-4}$ \\
\hline $31-5,148$ & 299.98 & -5.70 & $0.1766 \times 10^{-4}$ \\
\hline $32-1,60$ & 303.10 & -7.10 & $0.1204 \times 10^{-4}$ \\
\hline $32-2,54$ & 304.54 & -1.47 & $0.1019 \times 10^{-3}$ \\
\hline $32-2,74$ & 304.74 & -17.40 & $0.1360 \times 10^{-4}$ \\
\hline $32-7,4$ & 311.54 & -12.13 & $0.1078 \times 10^{-3}$ \\
\hline $33-1,79$ & 312.29 & 12.50 & $0.1235 \times 10^{-4}$ \\
\hline $33-2,54$ & 313.54 & -6.90 & $0.1655 \times 10^{-4}$ \\
\hline $33-2,102$ & 314.02 & -12.20 & $0.1085 \times 10^{-4}$ \\
\hline $33-3,32$ & 314.82 & -4.00 & $0.1339 \times 10^{-4}$ \\
\hline $33-3,144$ & 315.94 & -17.70 & $0.1034 \times 10^{-4}$ \\
\hline $33-4,4$ & 316.04 & 13.30 & $0.1300 \times 10^{-4}$ \\
\hline $33-4,90$ & 316.90 & -0.50 & $0.1533 \times 10^{-4}$ \\
\hline $33-5,8$ & 317.58 & 0.30 & $0.1968 \times 10^{-4}$ \\
\hline $34-1,5$ & 321.05 & 0.30 & $0.9215 \times 10^{-5}$ \\
\hline $34-1,106$ & 322.06 & 14.70 & $0.3583 \times 10^{-4}$ \\
\hline $34-2,16$ & 322.66 & 27.00 & $0.3186 \times 10^{-4}$ \\
\hline $34.2,85$ & 323.35 & 34.50 & $0.4666 \times 10^{-4}$ \\
\hline $35-1,54$ & 331.04 & 19.03 & $0.1769 \times 10^{-3}$ \\
\hline $35-2,9$ & 332.09 & -14.90 & $0.2281 \times 10^{-4}$ \\
\hline $35-2,11$ & 332.11 & -10.40 & $0.1217 \times 10^{-4}$ \\
\hline $35-3,62$ & 332.62 & -4.70 & $0.8203 \times 10^{-5}$ \\
\hline $35-2,133$ & 333.33 & 20.74 & $0.9252 \times 10^{-4}$ \\
\hline $35-3,77$ & 334.27 & 35.00 & $0.5248 \times 10^{-4}$ \\
\hline $35-3,92$ & 334.42 & 47.20 & $0.1025 \times 10^{-3}$ \\
\hline
\end{tabular}

sphere in which these sediments were deposited is unknown, polarity is indeterminate, and (2) because secular variation of the earth's field has not been averaged out in these samples, these changes in inclination could reflect cycles of secular change instead of true magnetic reversals.

The sedimentation rates for this hole were estimated at 25 to $40 \mathrm{~m} / \mathrm{m}$.y. for Cores 17 to 21 and in excess of 39 $\mathrm{m} / \mathrm{m}$.y. for Cores 22 to 35 . The individual samples have an average depositional interval of roughly 400 to 1000 years (for cubic versus cylindrical samples) for Cores 17 to 21 and 25 to 64 years for Cores 22 to 35 . Because the sedimentation rate is so high, it seems more likely that the inclinations measured in this hole reflect the secular variations of the earth's magnetic field rather than the dipolar field configuration.

\section{SUMMARY}

Paleomagnetic studies of sediments from Leg 59 sites suggest that the sediments were deposited in a nearequatorial latitude. At two of the sites, sedimentation rates were exceptionally high; in these particular samples the secular variation of the earth's magnetic field may not have been averaged out. Definitive polarity designations are not possible in these samples, although a few intervals suggest consistent polarity. Proximity to the equator and high sedimentation rates contribute to the problem.

Using the sedimentation rates cited in this volume (and assuming constant sedimentation), we estimate that we sampled an interval of 3.3 m.y. in Hole 448 . Samples were taken at roughly 140,000-year intervals (using the crude mode of the sampling intervals), and each sample represented from 300 to 800 years. In Hole 450 , approximately 180,000 years were represented in the sediments of Cores 17 to 21; this interval was sampled approximately every 28,000 years, and each sample represented roughly 400 to 1000 years. In the lower portion of this hole, Cores 22 to 35 , we estimated that we sampled a stratigraphic sequence deposited in approximately 359,000 years. The sequence was sampled roughly at 18,000-year intervals (on the basis of the mean sampling interval), and each sample represented 25 to 64 years of sedimentation.

If we use the standard deviation to compare the scatter of inclinations within these sedimentary sequences, we find that the scatter is quite similar. For the Hole 448 sequence, the standard deviation was $11.9^{\circ}$. The standard deviation for the upper section of Hole 450 was $12.5^{\circ}$ and for the lower section, $11.4^{\circ}$. The spread of paleoinclinations is surprisingly consistent for these cores. The scatter may be viewed as a reflection of secular variation at the time of deposition. Alternatively, it may reflect an inherent capacity of the sediments to record magnetic directions. In the numerous previous studies of DSDP sediments, we found that the standard deviation typically is between $5^{\circ}$ and $18^{\circ}$. (These studies involved numerous sediment types, but all were typified by normal low oceanic sediment rates). thus, the amount of scatter in the high sedimentation rate cores is comparable to that of typical ocean basin cores. 
Table 3. Summary of NRM and demagnetized sample inclination and intensity, Hole 448.

\begin{tabular}{|c|c|c|c|c|c|c|}
\hline $\begin{array}{l}\text { Core/Section/Depth } \\
\text { (cm) }\end{array}$ & $\begin{array}{l}\text { Cleaning Level } \\
\text { (AF) }\end{array}$ & Stability Index ${ }^{\mathrm{a}}$ & $\begin{array}{l}\text { Declination } \\
\left({ }^{\circ}\right)\end{array}$ & $\begin{array}{l}\text { Inclination } \\
\left({ }^{\circ}\right)\end{array}$ & $\begin{array}{c}\text { Normalized Intensity } \\
{[\mathrm{J}(\mathrm{H}) / \mathrm{J}(\mathrm{O})]}\end{array}$ & $\begin{array}{l}\text { Intensity } \\
\left(\mathrm{emu} / \mathrm{cm}^{3}\right)\end{array}$ \\
\hline $4-6,132$ & 0.0 & 1390.011 & 14.40 & -59.20 & 1.0000 & $0.3115 \times 10^{-4}$ \\
\hline $4-6,132$ & 50.0 & 1180.109 & 304.19 & 0.28 & 0.8864 & $0.2761 \times 10^{-4}$ \\
\hline $4-6,132$ & 100.0 & 386.956 & 283.54 & -16.57 & 0.5451 & $0.1698 \times 10^{-4}$ \\
\hline $4-6,132$ & 150.0 & 140.976 & 275.28 & -6.87 & 0.5287 & $0.1647 \times 10^{-4}$ \\
\hline $4-6,132$ & 200.0 & 27.912 & 274.13 & -6.07 & 0.4526 & $0.1410 \times 10^{-4}$ \\
\hline $20-1,5$ & 0.0 & 238.102 & 341.66 & -2.22 & 1.0000 & $0.1795 \times 10^{-3}$ \\
\hline $20-1,5$ & 100.0 & 144.289 & 327.22 & 16.72 & 5.3443 & $0.9593 \times 10^{-3}$ \\
\hline $20-1,5$ & 150.0 & 54.062 & 328.17 & 19.27 & 4.2189 & $0.7573 \times 10^{-3}$ \\
\hline $20-2,143$ & 0.0 & 32.942 & 115.06 & 2.18 & 1.0000 & $0.2156 \times 10^{-3}$ \\
\hline $20-2,143$ & 100.0 & 35.528 & 112.70 & -0.12 & 1.4587 & $0.3145 \times 10^{-3}$ \\
\hline $20-2,143$ & 150.0 & 38.103 & 113.90 & 1.36 & 1.1104 & $0.2394 \times 10^{-3}$ \\
\hline $24-1,61$ & 0.0 & 33.493 & 301.83 & -3.28 & 1.0000 & $0.9606 \times 10^{-3}$ \\
\hline $24-1,61$ & 100.0 & 42,806 & 303.05 & -0.16 & 0.7990 & $0.7676 \times 10^{-3}$ \\
\hline $24-1,61$ & 150.0 & 52.112 & 303.85 & -2.64 & 0.6076 & $0.5837 \times 10^{-3}$ \\
\hline $24-2,79$ & 0.0 & 282.651 & 6.10 & -5.35 & 1.0000 & $0.8032 \times 10^{-3}$ \\
\hline $24-2,79$ & 25.0 & 262.384 & 13.13 & -4.38 & 0.9821 & $0.7888 \times 10^{-3}$ \\
\hline $24-2,79$ & 50.0 & 157.702 & 18.14 & -1.00 & 0.9112 & $0.7319 \times 10^{-3}$ \\
\hline $24-2,79$ & 100.0 & 114.207 & 16.87 & -4.46 & 0.7478 & $0.6006 \times 10^{-3}$ \\
\hline $24-2,79$ & 150.0 & 101.139 & 18.77 & 3.04 & 0.5763 & $0.4629 \times 10^{-3}$ \\
\hline $24-2,79$ & 200.0 & 47.181 & 21.09 & 3.58 & 0.4288 & $0.3444 \times 10^{-3}$ \\
\hline $24-2,79$ & 300.0 & 46.810 & 16.44 & 2.99 & 0.2464 & $0.1979 \times 10^{-3}$ \\
\hline $25-1,55$ & 0.0 & 85.540 & 159.80 & -3.65 & 1.0000 & $0.3663 \times 10^{-3}$ \\
\hline $25-1,55$ & 100.0 & 61.922 & 167.25 & -7.88 & 0.7387 & $0.2706 \times 10^{-3}$ \\
\hline $25-1,55$ & 150.0 & 38.785 & 167.84 & -9.73 & 0.5408 & $0.1981 \times 10^{-3}$ \\
\hline $25-3,91$ & 0.0 & 103.750 & 296.85 & 6.66 & 1.0000 & $0.4039 \times 10^{-3}$ \\
\hline $25-3,91$ & 50.0 & 100.188 & 298.16 & 11.63 & 0.8049 & $0.3251 \times 10^{-3}$ \\
\hline $25-3,91$ & 100.0 & 114.471 & 298.41 & 16.51 & 0.5875 & $0.2373 \times 10^{-3}$ \\
\hline $25-3,91$ & 150.0 & 78.621 & 298.80 & 9.96 & 0.4434 & $0.1791 \times 10^{-3}$ \\
\hline $25-3,91$ & 200.0 & 25.860 & 299.63 & 8.95 & 0.3580 & $0.1446 \times 10^{-3}$ \\
\hline $25-3,91$ & 300.0 & 25.703 & 297.13 & 9.68 & 0.2010 & $0.8117 \times 10^{-4}$ \\
\hline $26-1,112$ & 0.0 & 107.856 & 182.78 & -11.86 & 1.0000 & $0.8816 \times 10^{-4}$ \\
\hline $26-1,112$ & 25.0 & 114.795 & 180.54 & -13.43 & 1.0222 & $0.9012 \times 10^{-4}$ \\
\hline $26-1,112$ & 50.0 & 103.489 & 183.44 & -12.29 & 1.0008 & $0.8823 \times 10^{-4}$ \\
\hline $26-1,112$ & 100.0 & 79.244 & 182.20 & -16.36 & 0.7938 & $0.6998 \times 10^{-4}$ \\
\hline $26-1,112$ & 200.0 & 52.533 & 184.90 & -9.49 & 0.4044 & $0.3565 \times 10^{-4}$ \\
\hline $26-1,112$ & 300.0 & 31.384 & 181.83 & -8.69 & 0.1974 & $0.1740 \times 10^{-4}$ \\
\hline $26-2,48$ & 0.0 & 188.534 & 170.72 & 62.50 & 1.0000 & $0.5737 \times 10^{-3}$ \\
\hline $26-2,48$ & 100.0 & 160.741 & 132.26 & 56.17 & 0.7075 & $0.4059 \times 10^{-3}$ \\
\hline $26-2,48$ & 150.0 & 98.202 & 128.03 & 60.62 & 0.5017 & $0.2878 \times 10^{-3}$ \\
\hline $27-1,102$ & 0.0 & 40.377 & 152.32 & 0.69 & 1.0000 & $0.1787 \times 10^{-2}$ \\
\hline $27-1,102$ & 100.0 & 58.820 & 148.54 & 2.11 & 1.0285 & $0.1838 \times 10^{-2}$ \\
\hline $27-1,102$ & 150.0 & 77.284 & 147.53 & -1.62 & 0.9049 & $0.1617 \times 10^{-2}$ \\
\hline $29-1,60$ & 0.0 & 13.622 & 9.85 & -15.53 & 1.0000 & $0.2035 \times 10^{-3}$ \\
\hline $29-1,60$ & 100.0 & 11.739 & 11.25 & -15.34 & 0.8206 & $0.1670 \times 10^{-3}$ \\
\hline $29 \cdot 1,60$ & 150.0 & 9.844 & 10.75 & -15.44 & 0.6265 & $0.1275 \times 10^{-3}$ \\
\hline $31-1,16$ & 0.0 & 2071.825 & 278.55 & -13.00 & 1.0000 & $0.2313 \times 10^{-4}$ \\
\hline $31-1,16$ & 10.0 & 1611.059 & 279.15 & 7.71 & 0.9395 & $0.2173 \times 10^{-4}$ \\
\hline $31-1,16$ & 25.0 & 1063.160 & 285.99 & -8.16 & 1.1012 & $0.2547 \times 10^{-4}$ \\
\hline $31-1,16$ & 50.0 & 714.794 & 272.35 & 12.28 & 1.1332 & $0.2621 \times 10^{-4}$ \\
\hline $31-1,16$ & 100.0 & 406.804 & 295.36 & 18.41 & 1.0463 & $0.2420 \times 10^{-4}$ \\
\hline $31-1,16$ & 150.0 & 435.024 & 179.80 & 9.03 & 0.9105 & $0.2106 \times 10^{-4}$ \\
\hline $31-1,16$ & 200.0 & 482.158 & 260.96 & -8.37 & 0.5249 & $0.1214 \times 10^{-4}$ \\
\hline $31-1,16$ & 300.0 & 454.342 & 302.78 & 11.14 & 0.2990 & $0.6915 \times 10^{-5}$ \\
\hline
\end{tabular}

a Millidegrees per Oe.

On the basis of the paleomagnetic directions from the sediments collected at DSDP Sites 448 and 450 , it would appear that both sites were close to the equator when the sediments were being deposited. The mean paleolatitudes calculated from the sediments from Site 448 were -1 to $5^{\circ}$. At Site 450 , two paleolatitudes were determined, because it was unclear whether the site was situated at the equator or displaced slightly to the north or south. The means indicate that the sediments were deposited between $0^{\circ}$ and $5^{\circ}$ latitude. There is no shallowing trend in paleoinclinations apparent in the stratigraphic plots of the data. Thus we cannot determine whether these sites were north or south of the equator. The absence of a trend in the paleolatitude is not unexpected, however, since the sedimentation rates are so high and it is unlikely that secular variation is being averaged out.
The variation in latitude due to secular variation probably outweighs the variation due to plate motion. Sites 448 and 450 are presently situated at about $18^{\circ} \mathrm{N}$ latitude. We can infer from the differences in the present and paleolatitudes that both sites have undergone significant northward motion. In the case of Site 448, the differences in latitudes suggest at least $8^{\circ}$ of northward motion has occurred during the last $31 \mathrm{~m} . \mathrm{y}$. If the site moved from the Southern Hemisphere, up to $30^{\circ}$ of northward motion could be inferred. The difference in latitude for Site 450 is consistent with roughly $13^{\circ}$ to $23^{\circ}$ of northward motion in the last 17 m.y.

\section{ACKNOWLEDGMENTS}

I would like to thank E. Herrero and V. Hsü for their help with computer programs and for aiding in the measurement of the samples. This chapter is Hawaii Institute of Geophysics Contribution Number 1057. 

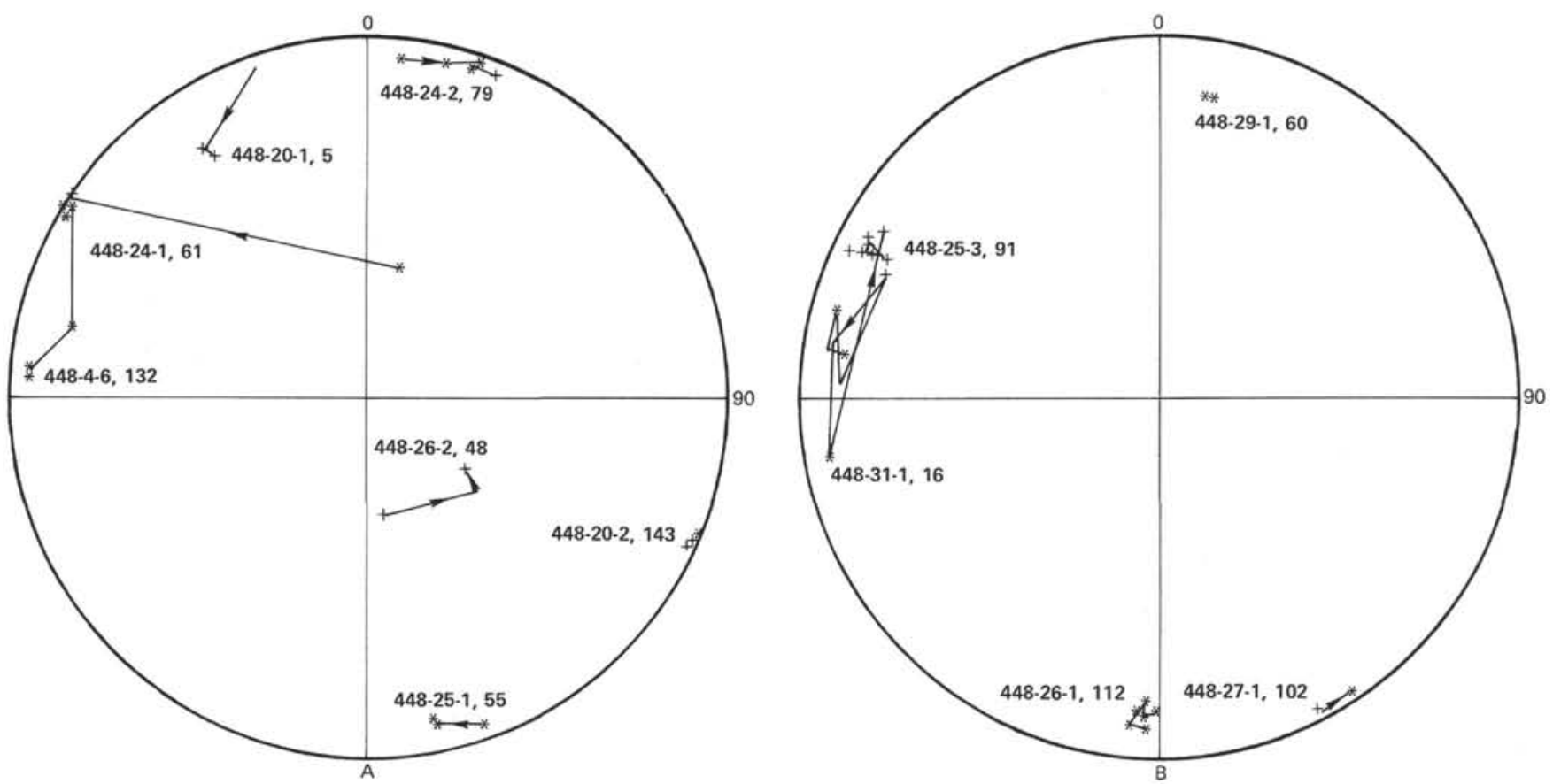

Figure 4. (A and B) Stereographic projections of natural remanent magnetization and demagnetized directions for samples from Hole 448. (Arrows indicate direction change upon progressive demagnetization, stars = negative inclination, and crosses $=$ positive inclination.)
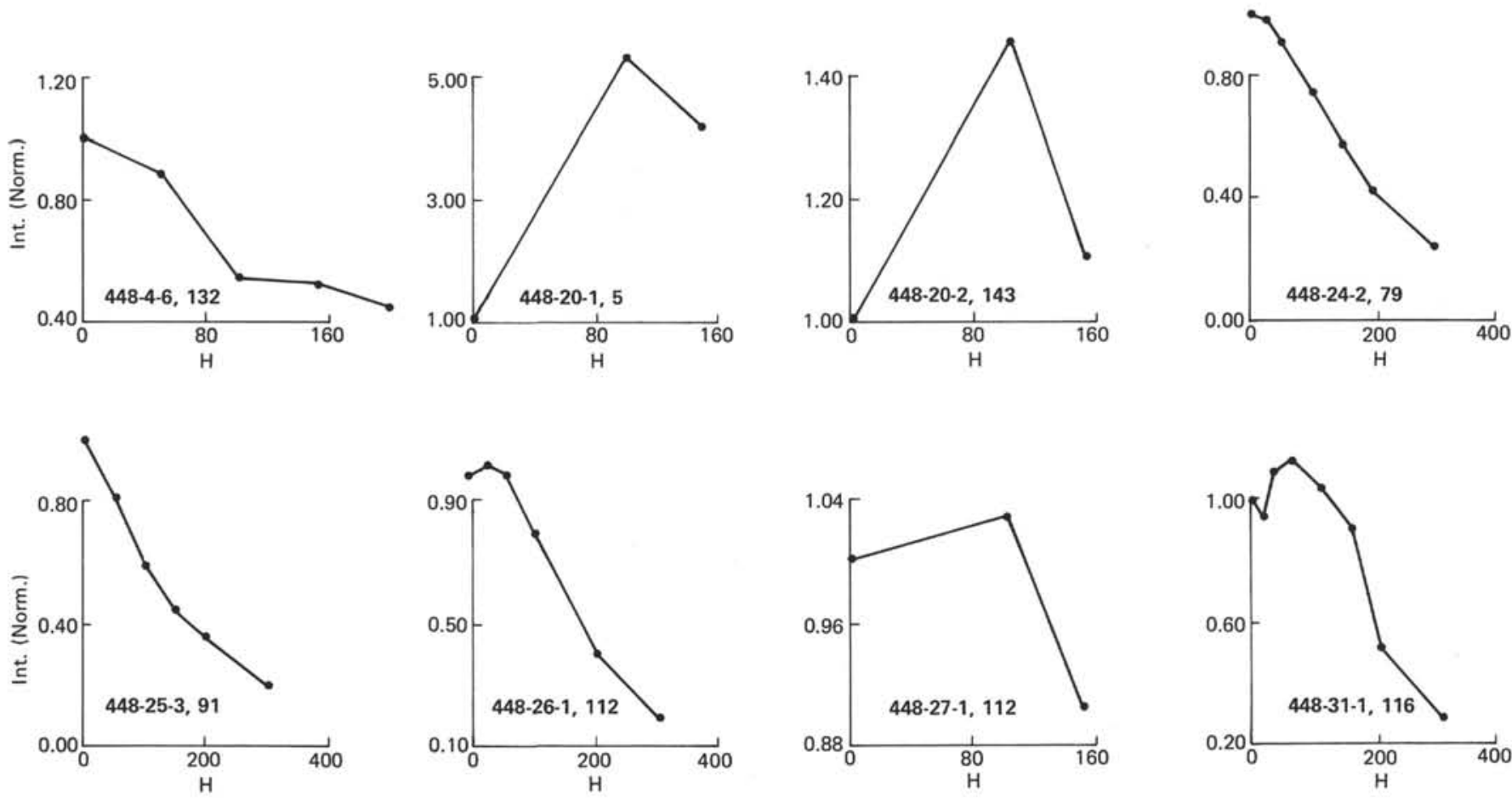

Figure 5. Plots of normalized intensity versus demagnetization level for select samples from Hole 448. (Peak demagnetization fields range from 160 to $400 \mathrm{Oe}$.)

\section{REFERENCES}

Johnson, H. P., Kinoshita, H., and Merrill, R. T., 1975. Rock magnetism and paleomagnetism of some North Pacific deep-sea sediments. Geol. Soc. Am. Bull., 86:412-420.

Keating, B. H., and Helsley, C. E., 1978a. Magnetostratigraphy of Cretaceous age sediments from Sites 361, 363, and 364. In Bolli,
H. M., Ryan, W. B. F., et al., Init. Repts. DSDP, 40: Washington (U.S. Govt. Printing Office), 459-468.

, 1978b. Paleomagnetic results from DSDP Hole $391 \mathrm{C}$ and the magnetostratigraphy of Cretaceous sediments from the Atlantic Ocean floor. In Benson, W. E., Sheridan, R. E., et al., Init. Repts. DSDP, 44: Washington (U.S. Govt. Printing Office), 523-528.

Opdyke, N. D., and Foster, T. H., 1970. Paleomagnetism of cores from the North Pacific. Geol. Soc. Am. Mem., 126:83-119. 

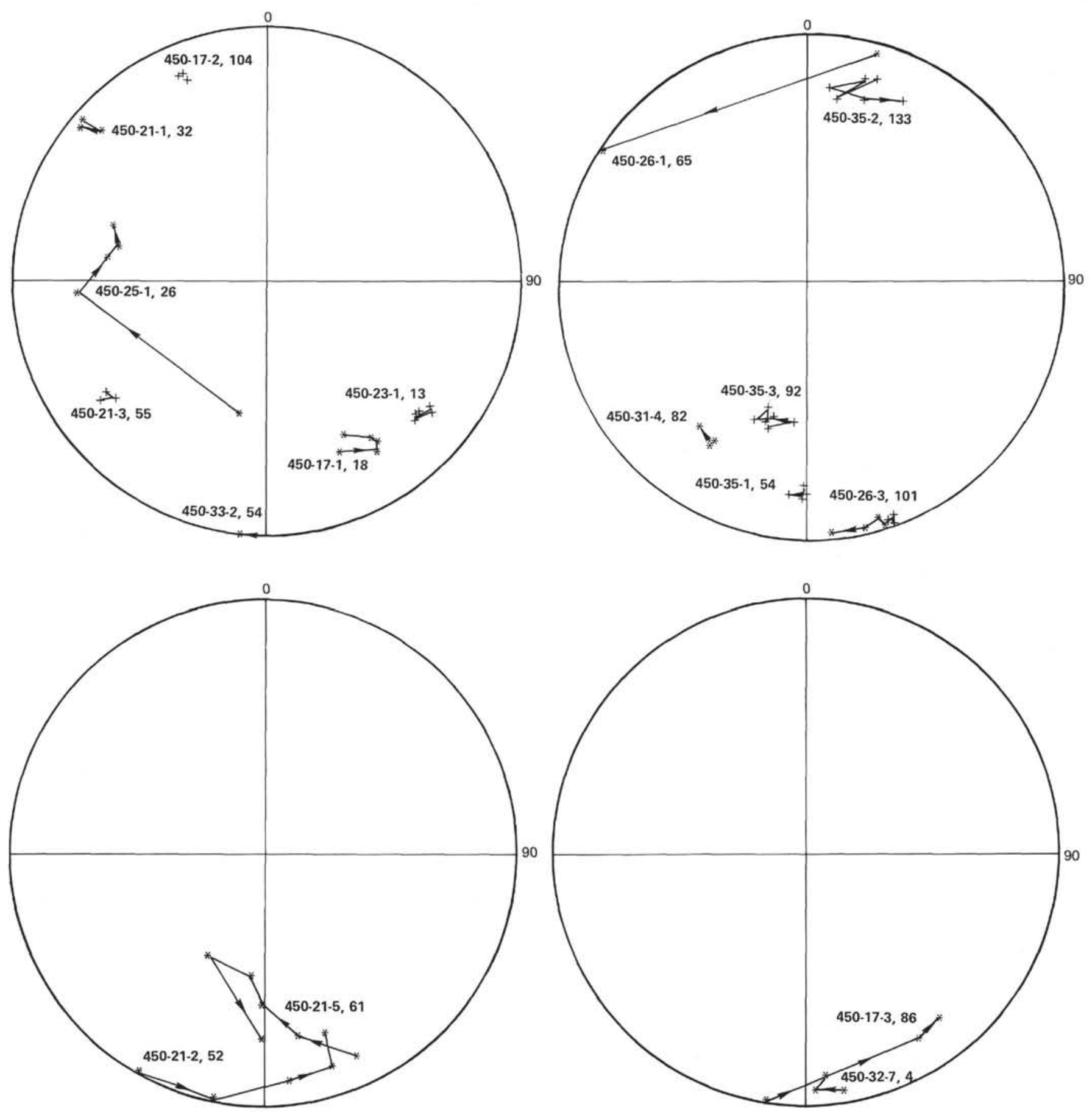

Figure 6. Stereographic projections of the changes of sample directions with progressive demagnetization. (Stars $=$ negative inclination and crosses $=$ positive inclination. . 
Table 4. Summary of NRM and demagnetized sample inclination and intensity, Hole 450.

\begin{tabular}{|c|c|c|c|c|c|c|}
\hline $\begin{array}{l}\text { Core/Section/Depth } \\
\text { (cm) }\end{array}$ & $\begin{array}{l}\text { Cleaning Level } \\
\text { (AF) }\end{array}$ & Stability Index ${ }^{a}$ & $\begin{array}{c}\text { Declination } \\
\left({ }^{\circ}\right)\end{array}$ & $\begin{array}{c}\text { Inclination } \\
\left({ }^{\circ}\right)\end{array}$ & $\begin{array}{l}\text { Normalized Intensity } \\
\qquad[\mathrm{J}(\mathrm{H}) / \mathrm{J}(\mathrm{O})]\end{array}$ & $\begin{array}{l}\text { Intensity } \\
\left(\mathrm{emu} / \mathrm{cm}^{3}\right)\end{array}$ \\
\hline $17-1,18$ & 0.0 & 217.941 & 155.67 & -27.77 & 1.0000 & $0.4181 \times 10^{-3}$ \\
\hline $17-1,18$ & 50.0 & 137.206 & 145.55 & -21.56 & 1.0591 & $0.4428 \times 10^{-3}$ \\
\hline $17-1,18$ & 100.0 & 54.661 & 144.24 & -23.69 & 0.9751 & $0.4077 \times 10^{-3}$ \\
\hline $17-1,18$ & 150.0 & 107.492 & 145.02 & -26.63 & 0.7847 & $0.3281 \times 10^{-3}$ \\
\hline $17-1,18$ & 200.0 & 154.552 & 151.43 & -32.13 & 0.6140 & $0.2567 \times 10^{-3}$ \\
\hline $17-2,104$ & 0.0 & 24.972 & 335.16 & 14.03 & 1.0000 & $0.7463 \times 10^{-3}$ \\
\hline $17-2,104$ & 100.0 & 20.440 & 336.21 & 16.31 & 0.8499 & $0.6343 \times 10^{-3}$ \\
\hline $17-2,104$ & 150.0 & 15.952 & 335.83 & 17.02 & 0.7041 & $0.5255 \times 10^{-3}$ \\
\hline $17-3,86$ & 0.0 & 441.744 & 189.52 & -1.62 & 1.0000 & $0.3210 \times 10^{-4}$ \\
\hline $17-3,86$ & 100.0 & 281.319 & 147.67 & -15.81 & 3.3645 & $0.1080 \times 10^{-3}$ \\
\hline $17-3,86$ & 150.0 & 135.699 & 140.78 & -17.50 & 2.7059 & $0.8686 \times 10^{-4}$ \\
\hline $21-1,32$ & 0.0 & 67.007 & 310.70 & -12.33 & 1.0000 & $0.1493 \times 10^{-2}$ \\
\hline $21-1,32$ & 100.0 & 105.717 & 308.51 & -5.98 & 0.9089 & $0.1357 \times 10^{-2}$ \\
\hline $21-1,32$ & 150.0 & 144.302 & 309.24 & -13.16 & 0.7709 & $0.1151 \times 10^{-2}$ \\
\hline $21-2,52$ & 0.0 & 370.592 & 209.86 & -1.71 & 1.0000 & $0.8553 \times 10^{-4}$ \\
\hline $21-2,52$ & 50.0 & 389.606 & 191.33 & -2.25 & 0.9270 & $0.7929 \times 10^{-4}$ \\
\hline $21-2,52$ & 100.0 & 312.655 & 172.90 & -11.86 & 0.8166 & $0.6984 \times 10^{-4}$ \\
\hline $21-2,52$ & 150.0 & 232.584 & 161.91 & -13.65 & 0.6470 & $0.5534 \times 10^{-4}$ \\
\hline $21-2,52$ & 200.0 & 248.596 & 161.36 & -26.07 & 0.4597 & $0.3932 \times 10^{-4}$ \\
\hline $21-3,55$ & 0.0 & 13.223 & 233.47 & 25.14 & 1.0000 & $0.3686 \times 10^{-3}$ \\
\hline $21-3,55$ & 100.0 & 40.215 & 232.05 & 25.45 & 0.8329 & $0.3070 \times 10^{-3}$ \\
\hline $21-3,55$ & 150.0 & 67.239 & 233.26 & 22.28 & 0.6612 & $0.2437 \times 10^{-3}$ \\
\hline $21-5,61$ & 0.0 & 419.870 & 155.18 & -12.36 & 1.0000 & $0.1588 \times 10^{-3}$ \\
\hline $21-5,61$ & 50.0 & 349.361 & 169.63 & -27.90 & 0.6417 & $0.1019 \times 10^{-3}$ \\
\hline $21-5,61$ & 100.0 & 247.610 & 180.35 & -40.26 & 0.5005 & $0.7948 \times 10^{-4}$ \\
\hline $21-5,61$ & 150.0 & 229.166 & 186.78 & -49.27 & 0.3932 & $0.6244 \times 10^{-4}$ \\
\hline $21-5,61$ & 200.0 & 297.425 & 207.31 & -51.46 & 0.2799 & $0.4445 \times 10^{-4}$ \\
\hline $21-5,61$ & 300.0 & 335.298 & 180.70 & -27.62 & 0.2320 & $0.3684 \times 10^{-4}$ \\
\hline $23-1,13$ & 0.0 & 92.669 & 131.21 & 21.11 & 1.0000 & $0.5683 \times 10^{-3}$ \\
\hline $23-1,13$ & 50.0 & 81.834 & 127.38 & 18.16 & 0.9446 & $0.5368 \times 10^{-3}$ \\
\hline $23-1,13$ & 100.0 & 52.077 & 129.86 & 20.78 & 0.7304 & $0.4151 \times 10^{-3}$ \\
\hline $23-1,13$ & 150.0 & 49.669 & 129.43 & 19.12 & 0.5965 & $0.3390 \times 10^{-3}$ \\
\hline $23-1,13$ & 200.0 & 65.158 & 132.28 & 21.00 & 0.4529 & $0.2574 \times 10^{-3}$ \\
\hline $25-1,26$ & 0.0 & 1109.900 & 190.65 & -45.99 & 1.0000 & $0.1457 \times 10^{-3}$ \\
\hline $25-1,26$ & 50.0 & 827.055 & 265.67 & -26.94 & 1.5758 & $0.2296 \times 10^{-3}$ \\
\hline $25-1,26$ & 100.0 & 186.843 & 276.99 & -36.45 & 1.2395 & $0.1806 \times 10^{-3}$ \\
\hline $25-1,26$ & 150.0 & 100.119 & 283.13 & -39.25 & 1.0391 & $0.1514 \times 10^{-3}$ \\
\hline $25-1,26$ & 200.0 & 89.878 & 287.92 & -36.90 & 0.8229 & $0.1199 \times 10^{-3}$ \\
\hline $26-1,65$ & 0.0 & 719.478 & 14.98 & -6.55 & 1.0000 & $0.1805 \times 10^{-3}$ \\
\hline $26-1,65$ & 100.0 & 409.420 & 302.70 & -2.07 & 1.4753 & $0.2663 \times 10^{-3}$ \\
\hline $26-1,65$ & 150.0 & 95.125 & 303.43 & 2.63 & 1.2438 & $0.2245 \times 10^{-3}$ \\
\hline $26-3,101$ & 0.0 & 85.874 & 158.89 & 3.31 & 1.0000 & $0.1489 \times 10^{-3}$ \\
\hline $26-3,101$ & 25.0 & 64.742 & 159.56 & 1.27 & 1.0813 & $0.1610 \times 10^{-3}$ \\
\hline $26-3,101$ & 50.0 & 67.398 & 159.97 & 2.28 & 1.2297 & $0.1831 \times 10^{-3}$ \\
\hline $26-3,101$ & 100.0 & 81.624 & 161.46 & -2.03 & 1.2122 & $0.1805 \times 10^{-3}$ \\
\hline $26-3,101$ & 150.0 & 79.371 & 162.23 & -5.55 & 1.0141 & $0.1510 \times 10^{-3}$ \\
\hline $26-3,101$ & 200.0 & 81.979 & 166.04 & -3.47 & 0.7529 & $0.1121 \times 10^{-3}$ \\
\hline $26-3,101$ & 300.0 & 77.265 & 173.78 & -3.41 & 0.5268 & $0.7844 \times 10^{-4}$ \\
\hline $31-4,82$ & 0.0 & 14.329 & 212.46 & -28.92 & 1.0000 & $0.2446 \times 10^{-3}$ \\
\hline $31-4,82$ & 100.0 & 56.836 & 213.04 & -27.58 & 0.7081 & $0.1732 \times 10^{-3}$ \\
\hline $31-4,82$ & 150.0 & 99.320 & 218.20 & -29.72 & 0.5037 & $0.1232 \times 10^{-3}$ \\
\hline $32-7,4$ & 0.0 & 68.895 & 170.97 & -6.38 & 1.0000 & $0.2514 \times 10^{-3}$ \\
\hline $32-7,4$ & 100.0 & 81.361 & 177.61 & -8.36 & 0.5764 & $0.1449 \times 10^{-3}$ \\
\hline $32-7,4$ & 150.0 & 94.109 & 174.73 & -12.13 & 0.4288 & $0.1078 \times 10^{-3}$ \\
\hline $33-2,54$ & 0.0 & 52.123 & 180.03 & 0.47 & 1.0000 & $0.2208 \times 10^{-3}$ \\
\hline $33-2,54$ & 100.0 & 41.870 & 185.23 & 0.11 & 0.6526 & $0.1441 \times 10^{-3}$ \\
\hline $33-2,54$ & 150.0 & 31.616 & 185.18 & -1.47 & 0.4615 & $0.1019 \times 10^{-3}$ \\
\hline $35-1,54$ & 0.0 & 388.201 & 180.03 & 0.47 & 1.0000 & $0.2208 \times 10^{-3}$ \\
\hline $35-1,54$ & 50.0 & 210.531 & 179.99 & 19.88 & 1.5797 & $0.3488 \times 10^{-3}$ \\
\hline $35-1,54$ & 100.0 & 38.213 & 180.66 & 21.40 & 1.3152 & $0.2904 \times 10^{-3}$ \\
\hline $35-1,54$ & 150.0 & 44.848 & 181.55 & 19.39 & 1.0326 & $0.2280 \times 10^{-3}$ \\
\hline $35-1,54$ & 200.0 & 46.131 & 183.96 & 19.03 & 0.8012 & $0.1769 \times 10^{-3}$ \\
\hline $35-2,133$ & 0.0 & 271.394 & 197.74 & 16.37 & 1.0000 & $0.4814 \times 10^{-3}$ \\
\hline $35-2,133$ & 50.0 & 236.519 & 188.26 & 26.44 & 0.7148 & $0.3441 \times 10^{-3}$ \\
\hline $35-2,133$ & 100.0 & 211.807 & 195.36 & 18.41 & 0.5027 & $0.2420 \times 10^{-3}$ \\
\hline $35-2,133$ & 150.0 & 205.939 & 185.22 & 23.73 & 0.3972 & $0.1912 \times 10^{-3}$ \\
\hline $35-2,133$ & 200.0 & 151.424 & 196.05 & 24.95 & 0.2898 & $0.1395 \times 10^{-3}$ \\
\hline $35-2,133$ & 300.0 & 104.952 & 206.33 & 20.74 & 0.1922 & $0.9252 \times 10^{-4}$ \\
\hline $35-3,92$ & 0.0 & 142.092 & 195.54 & 42.08 & 1.0000 & $0.2995 \times 10^{-3}$ \\
\hline $35-3,92$ & 50.0 & 126.992 & 186.58 & 44.58 & 0.9072 & $0.2717 \times 10^{-3}$ \\
\hline $35-3,92$ & 100.0 & 114.043 & 194.82 & 44.91 & 0.7503 & $0.2247 \times 10^{-3}$ \\
\hline $35-3,92$ & 150.0 & 108.236 & 201.66 & 42.56 & 0.4725 & $0.1415 \times 10^{-3}$ \\
\hline $35-3,92$ & 200.0 & 70.556 & 198.00 & 47.20 & 0.3422 & $0.1025 \times 10^{-3}$ \\
\hline $35-3,92$ & 300.0 & 35.824 & 187.24 & 43.66 & 0.1988 & $0.5953 \times 10^{-4}$ \\
\hline
\end{tabular}

a Millidegrees per Oe. 
B. KEATING
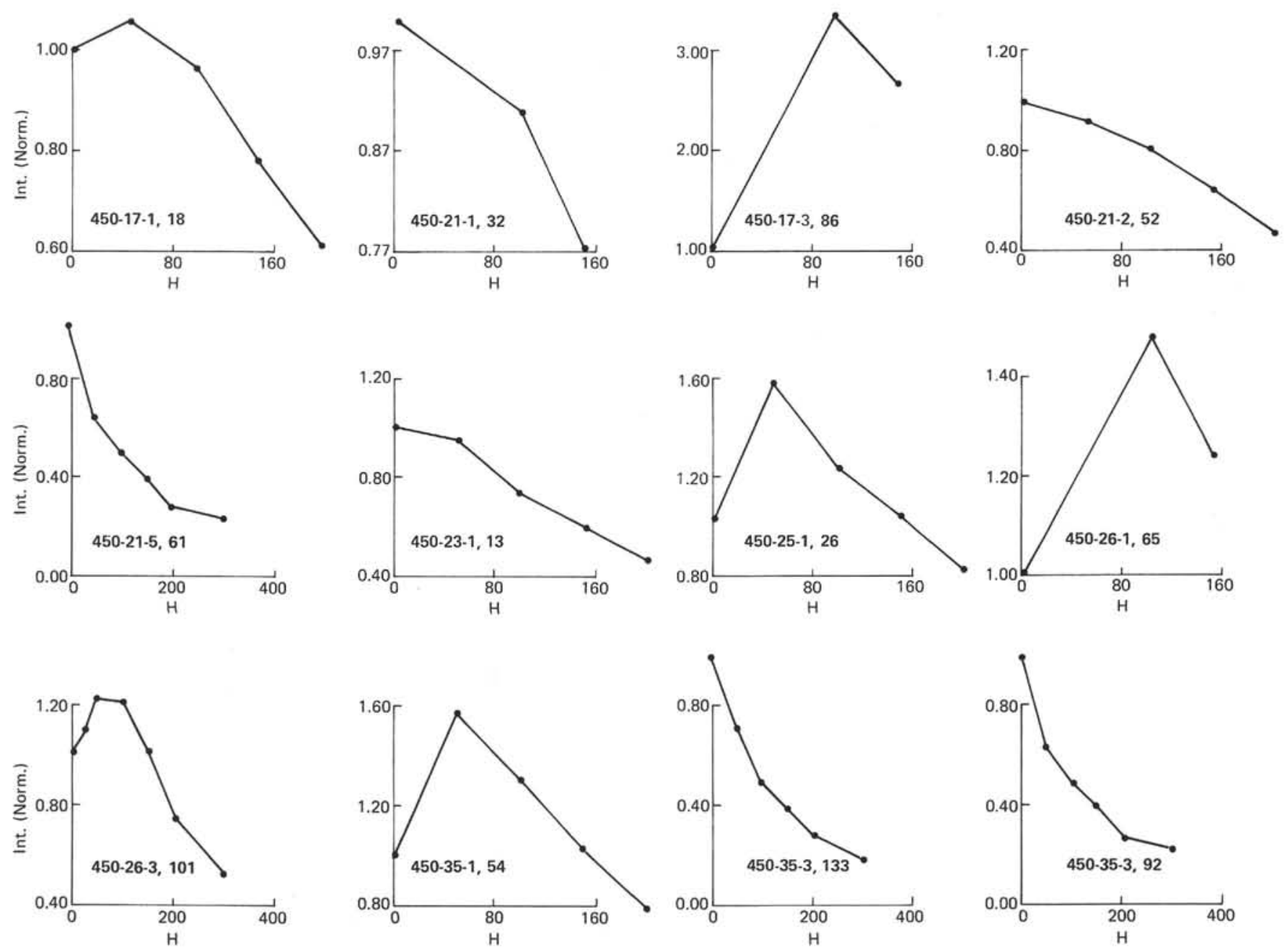

Figure 7. Plots of normalized intensity versus demagnetization field for select samples from Hole 450. (Peak demagnetization fields range from 160 to $400 \mathrm{Oe}$.) 